\title{
CONCEPTUAL DESIGN OF THERMAL ENERGY STORAGE SYSTEMS \\ FOR NEAR-TERM ELECTRIC UTILITY APPLICATIONS
}

\author{
Eldon W. Hall \\ General Electric Company
}

\section{PROJECT OUTLINE}

\author{
Project Title: Conceptual Design of Thermal Energy Storage (TES) Systems \\ for Near-Term Electric Utility Applications \\ Principal Investigator: El.don W. Hall \\ Organization: General Electric Company \\ Energy Technology Operation \\ 1 River Road \\ Schenectady, NY 12345 \\ Telephone: (518) 385-9090
}

Project Goals: Identify, design, and evaluate promising thermal energy storage systems for mid-term applications in conventional electric utilities for peaking power generation.

Evaluate candidate thermal energy storage systems and select the most promising concepts.

Complete conceptual designs of selected thermal energy storage systems integrated with conventional utilities.

Define characteristics of alternate systems for peaking power generation, viz gas turbines and coal fired cycling plants.

Perform competitive benefit analysis of thermal energy storage systems with alternate systems for peaking power generation.

Make recommendations for development and field test of thermal energy storage with a conventional utility.

Coordination with Electric Power Research Institute (Co-funder); Tennessee Valley Authority; DOE/Division of Electric Energy Systems

Project Status: Contract results were as follows:

Thermal energy storage was only marginally competitive with coal fired cycling power plants and gas turbines for peaking power generation.

A development and field test program does not appear viable to utilities at the present time.

Contract Number: DEN3-12 and EPRI RP 1082-1

Contract Period: December, 1977 to August, 1979

Funding Level: $\quad$ NASA $-\$ 360,000$, EPRI $-\$ 150,000$

Funding Source: NASA Lewis Research Center and Electric Power Research Institute 
CONCEPTUAL DESIGN OF THERMAL ENERGY STORAGE SYSTEMS FOR NEAR-

TERM ELECTRIC UTILITY APPLICATIONS

\author{
Eldon W. Hall \\ General Electric Company
}

This project makes a detailed evaluation of thermal energy storage (TES) for meeting peak power requirements of electric utilities. TES is made a part of the steam electric generating plant, storing therma 1 energy from steam or hot feedwater during low demand periods and using the thermal energy to generate electricity during peak demand periods.

While the steam turbine must still be sized to deliver the utility peak power, the steam generator can be designed at less than peak power (near average power) by using TES to supply energy to match the turbine requirements. Steam generator costs can therefore be less in a steam plant with TES than in one without TES where it must deliver peak power. These reduced costs are offset by the cost of the TES system and somewhat higher fuel use because of reduced efficiency. Less expensive baseload fuels, however, can be used to produce peak power.

Over forty TES concepts gleaned from the literature and personal contacts were examined for possible application.

Initial criteria for selection emphasized near-term availability and potential for economic feasibility. Many storage media, forms of containment, and cycle configurations for conversion to electricity were included in the concepts examined. Media included hot oil, molten salt or sulfur, rock or other solid media, and high temperature water. As the latter requires pressure vessels for containment at high temperature, such containment concepts as steel pressure vessels, prestressed cast iron vessels (PCIV), prestressed concrete pressure vessels (PCPV), and several concepts of containment in lined underground cavities were examined. 
The initial screening reduced the set to twelve selections, some of which combined the elements of several concepts. These selections were then applied to two reference plants, an 800 MW plant burning highsulfur coal, and an $1140 \mathrm{MW}$ plant utilizing a light water nuclear reactor. Results of analysis of performance and costs of the twelve TES plants led to approval of four options by DOE/NASA and EPRI for more detailed consideration and conceptual design.

Two of the options use high sulfur coal-fired plants (HSC) and peaking turbines to supply the peaking power from steam generated from the thermal energy stored during off-peak periods. Steam is withdrawn from the cycle after the high-pressure turbine during the off-peak period to obtain the required energy for storage. With peaking turbines, power swings of \pm 50 percent of the normal power are possible. One of the coal concepts stores the thermal energy in a dual media of a bed of rock with pores filled with hot oil at low pressure as a heat transfer medium. The other option uses an underground cavity lined with steel to store hot water under high pressure. Concrete is used to transfer the stress from the liner to the supporting rock.

The other two options utilize conventional nuclear plants and obtain power variations by reducing the feedwater extraction during peak power periods and increasing the extraction during off-peak periods. The thermal energy of the hot feedwater during the off-peak periods is stored to heat feedwater during the peak periods. Because of limitations on feedwater extraction, power swings are limited to \pm 10 to 15 percent of normal power. One of the concepts utilizes the PCIV for storage of hot feedwater and the other utilizes the dual media, hot oil and rock, to store the feedwater thermal energy.

To avoid difficult design problems in coal-fired boilers with reheaters when large quantities of steam are withdrawn at the HP turbine outlet, the coal plants for TES were designed without reheaters resulting in small increases in both cost and heat rate. 
Based on the conceptual designs, the cost and performance of the four TES systems as well as reference nuclear and coal plants were determined. The EPRI Technical Assessment Guide (TAG) (8/77) was used as a basis for the reference plants and fuel and operating costs. Costs of the other systems were made as consistent as possible with the TAG basis. A total installed cost in mid-1.976 dollars and a levelized busbar energy cost was found for each plant assuming a 30-year life beginning operation in 1990.

Cycling coal plants were considered as a possible alternative to TES systems for peak load following. Performance and cost estimates on the same basis as the other plants were therefore made for two $512 \mathrm{MW}$ cycling plants, one at 1800 psig/ $/ 950^{\circ} \mathrm{F} / 950^{\circ} \mathrm{F}$ steam conditions and another at $2400 / 1000 / 1000$.

The 1977 Consent Decree places a number of restrictions on the General Electric Company regarding the furnishing of performance and pricing information on large steam turbine-generators. Accordingly, performance data, performance differences data and pricing information on steam turbine-generators included in this report are estimated data, for the most part calculated in 1976, but which are accurate enough for the intended purpose of this study.

The limited peaking capacity that results with feedwater energy storage reduces the benefit that the nuclear systems which were studied can provide a utility. These systems also have a high cost increment for peaking in both capital and levelized busbar electricity costs.

The coal plants with separate peaking turbines provide peaking power about equal to cycling coal plants in both total investment cost and levelized electricity cost. Both the TES and cycling coal plants are significantly lower in cost than the TES nuclear plants but still cannot compete with gas turbines for peaking duty at 1500 hours of operation or less per year unless oil becomes unavailable or increases significantly in cost. 
The significantly higher cost of the TES nuclear plants compared to the coal plants is attributed principally to the feedwater storage mode and the high cost of key TES components, not to the fact that these TES sys tems were integrated with a nuclear plant.

A major disadvantage of TES systems as compared to cycling coal plants or gas turbines is their limited capacity to operate at any time if required because of other system outages. Increasing TES system capacity, however, so that it can operate more hours per day increases the cost more than the benefits obtained.

The capital investment required for storage is generally equal to or greater than that for at least some types of complete generation equipment, especially peaking systems. Hence, if storage systems are to be viable, there must be an opportunity to displace some of the high fuel or production costs of peaking generation equipment with lower production costs of baseload or intermediate equipment. Any production cost savings which are possible will depend on the fuel costs and efficiencies of both the peaking and storage systems.

The values of the TES systems to utilities are sensitive to the cost difference between gas turbine fuel and coal. TES integrated with a coal plant could be competitive with gas turbines for peaking if the 1990 fuel cost differential between oil and coal becomes greater than $3.6 \$ / M B t u$ in 1976 dollars. The current EPRI estimate is a difference of $2.15 \$ /$ MBtu on the same basis.

While recent price increases in oil indicate that the differences could easily exceed the $3.6 \$ / M B t u$ in 1976 dollars by 1990 , the coal based TES systems still could not compete with the cycling coal plants. The nuclear based TES systems might compete only if they were designed to use peaking turbines and the cost of both oil and coal increased unreasonably relative to the cost of nuclear fuel. 
The TES systems meet the design objectives of being load following and daily cycling plants that are not dependent on scarce fue $1 \mathrm{~s}$. a $12 \%$ penetration of TES system plants into a typical generation mix (EPRI Utility System D) would reduce the system oil consumption by $32 \%(3.3$ million barrels per year). However, a $12 \%$ penetration by cycling coal plants in the same utility system would reduce oil consumption by $52 \%$.

None of the four TES systems, based on the near-term designs for this study, are economically attractive to utilities. Cost reductions of 10 to $40 \%$ are required for TES to be competitive with cycling coal plants and 40 to $50 \%$ if they are to be competitive with gas turbines at 1500 hours of annual operation. About one-half of the TES costs are related to the storage related items, with the remaining costs for standard state-of-the-art equipment such as turbines, piping, valving, etc. Reductions in total costs, therefore, must come almost entirely from reductions in the TES storage related costs.

Additonal testing and development work on large TES systems would be required prior to a major commitment to TES by utilities. This large scale demonstration would be required to substantiate the performance figures for final system designs. The study design performance parameters were all extrapolated from smaller storage applications.

While not investigated in this study, major redesigns of the base plants to incorporate alternate TES systems would be required to improve the performance of TES for peaking applications. These changes would increase their cost and eliminate their use in near-term applications.

Additional refinements of near-term TES plant designs to improve the economic competitiveness with alternate peaking systems, especially cycling coal plants, will probably yield only marginal improvements. 